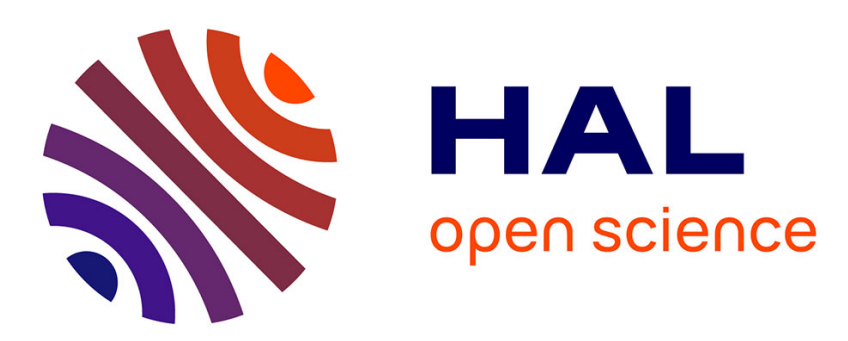

\title{
Glucocorticoids and Circadian Clock Control of Cell Proliferation: At the Interface between Three Dynamic Systems
}

Thomas Dickmeis, Nicholas S. Foulkes

\section{To cite this version:}

Thomas Dickmeis, Nicholas S. Foulkes. Glucocorticoids and Circadian Clock Control of Cell Proliferation: At the Interface between Three Dynamic Systems. Molecular and Cellular Endocrinology, 2010, 331 (1), pp.11. 10.1016/j.mce.2010.09.001 . hal-00639781

HAL Id: hal-00639781

https://hal.science/hal-00639781

Submitted on 10 Nov 2011

HAL is a multi-disciplinary open access archive for the deposit and dissemination of scientific research documents, whether they are published or not. The documents may come from teaching and research institutions in France or abroad, or from public or private research centers.
L'archive ouverte pluridisciplinaire HAL, est destinée au dépôt et à la diffusion de documents scientifiques de niveau recherche, publiés ou non, émanant des établissements d'enseignement et de recherche français ou étrangers, des laboratoires publics ou privés. 


\section{Accepted Manuscript}

Title: Glucocorticoids and Circadian Clock Control of Cell

Proliferation: At the Interface between Three Dynamic

Systems

Authors: Thomas Dickmeis, Nicholas S. Foulkes

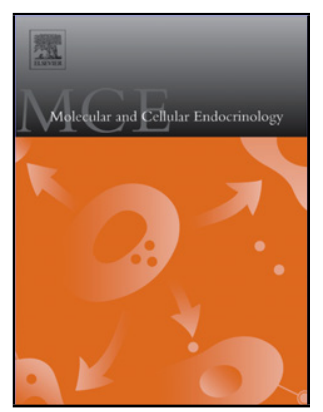

PII:

S0303-7207(10)00461-2

DOI:

doi:10.1016/j.mce.2010.09.001

Reference:

MCE 7632

To appear in:

Molecular and Cellular Endocrinology

Received date:

9-6-2010

Revised date:

$1-9-2010$

Accepted date:

$3-9-2010$

Please cite this article as: Dickmeis, T., Foulkes, N.S., Glucocorticoids and Circadian Clock Control of Cell Proliferation: At the Interface between Three Dynamic Systems, Molecular and Cellular Endocrinology (2010), doi:10.1016/j.mce.2010.09.001

This is a PDF file of an unedited manuscript that has been accepted for publication. As a service to our customers we are providing this early version of the manuscript. The manuscript will undergo copyediting, typesetting, and review of the resulting proof before it is published in its final form. Please note that during the production process errors may be discovered which could affect the content, and all legal disclaimers that apply to the journal pertain. 


\section{Glucocorticoids and Circadian Clock Control of Cell Proliferation:}

\section{At the Interface between Three Dynamic Systems}

Thomas Dickmeis and Nicholas S. Foulkes

ITG - Institute of Toxicology and Genetics, Karlsruhe Institute of Technology (KIT), Campus Nord, Postfach 3640, D-76021 Karlsruhe, Germany

The circadian clock, an endogenous timekeeper that regulates daily rhythms of physiology, also influences the dynamic release of glucocorticoids. The release of glucocorticoids is characteristically pulsatile and is further modulated in a circadian fashion. A circadian pacemaker in the brain regulates daily rhythms of hypothalamicpituitary-adrenal axis and autonomic nervous system activity that both influence glucocorticoid release from the adrenal gland. This systemic regulation interacts with rhythms in the adrenal gland itself that are driven by its own circadian clock. One function of glucocorticoids is the regulation of cell proliferation. Depending on the tissue, this can involve both negative and positive regulation of a variety of processes, including cell differentiation and cell death. Cell proliferation is also under circadian control, and recent evidence suggests that this regulation may involve glucocorticoid signalling. Here, we review the dynamic processes participating in the interplay between the circadian clock, glucocorticoids and cell proliferation, and we discuss the potential implications for therapy.

Key words: adrenal gland, cell proliferation, circadian clock, glucocorticoid, neurogenesis, signalling

Correspondence to: thomas.dickmeis@ @it.edu; nicholas.foulkes@kit.edu 


\section{Introduction - the circadian clock}

Among the many challenges that organisms face are the daily environmental changes brought about by the rotation of our planet on its axis. Endogenous timing mechanisms have evolved which allow organisms to anticipate these regular changes in the environment and so adapt to the specific needs of certain times of day in a timely manner. These mechanisms drive periodic changes in physiology even in the absence of environmental timing cues, such as under constant darkness and temperature. Under such conditions, physiological rhythms e.g. in locomotor behaviour run with an endogenous period that is slightly different from 24 hours. The biological clocks driving these rhythms are therefore termed "circadian", from Latin "circa" - "around" and "dies" - "day". Under constant conditions circadian clocks are said to "free-run", as they are not longer restrained by the environmental cues which serve to regularly reset or "entrain" them under natural conditions. Such cues, also called "Zeitgeber" (German for "time-givers"), include for example light and temperature, but also certain chemical compounds and social behaviour can entrain the clock [1].

The central clock in the brain

In mammals, a small hypothalamic nucleus has been demonstrated to play a crucial role for the generation of circadian rhythms: The suprachiasmatic nucleus, or SCN [2]. Ablation of this nucleus leads to arrhythmicity of behaviour and of hormonal secretion. Furthermore, elegant transplantation experiments in hamsters showed that this structure was indeed sufficient to drive behavioural rhythms: animals in which the SCN was ablated and that then received a SCN transplant showed restored rhythms [3]. When the transplant was derived from a mutant hamster strain that had a shorter endogenous period [4], the transplanted animals showed locomotor 
activity with the mutant period [3]. The SCN sends projections to a number of brain targets where its rhythmical electrical activity interacts with neural networks governing various outputs. However, also paracrine factors are involved in SCN output, since even encapsulated transplants, which do not allow neural connections, are able to restore locomotor rhythms in SCN ablated animals [5]. Interestingly, endocrine rhythms such as rhythmical melatonin and corticosteroid secretion are not restored by SCN transplants, suggesting a specific requirement for neural connections in their circadian control [6].

Information about the environmental lighting conditions reaches the $\mathrm{SCN}$ via the retinohypothalamic tract of the optic nerve (reviewed in [7]). Only a specific subset of retinal ganglion cells projects to the SCN. These cells are intrinsically photosensitive, as they express a photopigment, melanopsin (reviewed in [8,9]). Their function is crucial for entrainment of the SCN, since transgenic animals in which these cells are genetically ablated show free-running rhythms when exposed to light-dark cycles, just as normal animals do under constant darkness [10]. The photopigments of the rods and cones of the retina and melanopsin are highly redundant in this process, because only animals that lack both functional rods and cones and melanopsin show this "circadian blindness", whereas the presence of one of the two systems is sufficient to maintain circadian entrainment [11]. These findings may also explain why only certain blind people suffer from free-running circadian rhythms: If only their photoreceptor layer is affected, leaving the photosensitive retinal ganglion cells intact, they retain some light input into the circadian system in spite of visual blindness [12]. 


\section{The cogs of the clock}

Brain slice cultures of the SCN exhibit circadian rhythms of electrical activity, demonstrating that this structure is able to generate rhythms autonomously ([13] and references therein). However, this property is not due to a "neural oscillator circuit", since even single dissociated SCN neurons show circadian patterns of activity [14]! The circadian oscillator mechanism must therefore reside at the single cell level, a concept consistent with the observation of circadian rhythms in many unicellular organisms [15-17]. A wealth of genetic and biochemical studies has revealed the nature of the cellular oscillator mechanism in vertebrates [18]: An autoregulatory transcriptional-translational feedback loop leads to circadian oscillations of transcripts and proteins of a set of so-called clock genes (Fig.1, B). The feedback loop starts when transcription of the period and cryptochrome genes is activated by the binding of a heterodimer of the bHLH-PAS domain transcription factors CLOCK and BMAL1 to so-called E-box enhancer elements in their promoters. PER and CRY proteins then accumulate in the cytoplasm, where they are modified by posttranslational mechanisms that modulate their entry into the nucleus. Once in the nucleus, they inhibit the activity of the CLOCK-BMAL1 dimer and thereby inhibit the transcription of their own genes. Consequently, per and cry transcript and protein levels decline, and the repression of CLOCK-BMAL1 activity is released, allowing the cycle to start again. The various delays in this process, notably those brought about by posttranslational modifications [19], confer a cycle duration of roughly 24 hours. Such modifications include phosphorylation of core clock factors, e.g. of PER2, which is phosphorylated on several residues by the kinases CK1 $\delta$, CK1 $1 \varepsilon$ and CK2, [20-23] or of CRY1 by AMPK [24]. Other modifications include the ubiquitination of CRYs by F-box type ubiquitin ligases that targets them for 
degradation by the proteasome [25-27]. Furthermore, acetylation of BMAL1 and PER2 has been reported [28, 29].

The transcriptional-translational feedback loop described above defines the socalled "core loop" of the clock. Other feedback loops are thought to interact with this loop and to contribute to its robustness and fine tuning. The "accessory loop" consists of nuclear receptor transcription factors of the ROR and RevERB type, the transcription of which are again under control of the CLOCK-BMAL1 dimer [30]. RORs activate transcription of the bmall gene via a RORE (retinoic acid related orphan receptor response element) in its promoter, while the RevERBs, which bind this element after a certain delay, repress its transcription. The resulting oscillatory expression of BMAL1 is believed to reinforce the core loop oscillations.

\section{Clocks are everywhere}

Clock genes are not only expressed in the neurons of the SCN or in the other central pacemaker structures found in non-mammalian vertebrates (the retina and the pineal gland). Instead, they are expressed in nearly all tissues of the body and also show oscillating expression there [31]. Indeed, organ explants show circadian oscillations in some of their functions and in gene expression, demonstrating that they contain autonomous pacemakers [32-36]. Even the individual cells in fibroblast cell lines exhibit circadian rhythms in gene expression [37-39]. Thus, circadian clocks are not an exclusive property of SCN neurons. The "peripheral" oscillators appear to be coordinated by the "central" oscillator, the SCN, since they drift out of phase with respect to each other in animals in which the SCN has been ablated [35]. How exactly this coordination is achieved is still a field of active research, and cues proposed to mediate the synchronisation include body temperature changes [40], food derived signals [41-43] and also glucocorticoids ([44, 45], see below). The importance of the 
peripheral oscillators for circadian organisation in vivo becomes apparent when the clock is stopped only in specific tissues by tissue-specific gene knock-out or knockdown techniques. For example, in mice that carry a liver specific deletion of the bmall gene which stops the clock in this tissue, one observes a deregulation of the circadian gene expression of many metabolic genes as well as a fasting glycemia [46]. However, circadian expression of certain genes in the liver is driven by systemic mechanisms, as they continue to cycle when the liver clock is stopped [47]. Systemic circadian changes more directly controlled by the SCN, e.g. in autonomic nervous system activity, also contribute to the daily regulation of glucose levels by the liver [48].

\section{The circadian timing of metabolism}

As shown by the example above, circadian clocks are involved in various aspects of metabolic regulation, both systemically and locally. Many rate-limiting enzymes of metabolic pathways show circadian expression [49], and disturbance of the circadian clock can lead to phenotypes resembling human metabolic diseases [50]. It becomes increasingly apparent that metabolism in turn can also feed back on the clock: as already mentioned above, the nutrient sensing kinase AMPK phosphorylates CRY1 and thereby destabilizes it [24]. The histone deacetylase SIRT1 deacetylates not only histones, but also the core clock components BMAL1 and PER2 (most likely previously acetylated by CLOCK itself, which has HAT activity [28]), and it requires NAD+ as a cofactor $[29,51-53]$. NAD+ levels show circadian oscillation, partially mediated by clock control of the rate limiting enzyme in NAD+ biosynthesis, nicotinamide phosphoribosyltransferase. This complicated interplay of central and peripheral clocks, of cell autonomous and systemic regulation and of feedback from clock outputs to the clocks themselves is still poorly understood. 


\section{Clock control of cell proliferation}

Another highly temporally regulated event is cell proliferation, and it is perhaps not too surprising that the timing of cell proliferation and the circadian clock may be coupled (Fig. 1, C). Indeed, circadian rhythms in cell proliferation are observed across a wide range of organisms, from cyanobacteria and unicellular algae to humans, suggesting an early evolutionary origin and strong adaptive value for this cell cycle control [54-57]. Since the circadian timing of the cell cycle shows a tendency to place $\mathrm{S}$ phase and mitosis in the night period, it has been suggested that the main adaptive pressure for circadian cell cycle control might stem from environmental UV light and its harmful effects on DNA replication and mitosis [58, 59].

\section{Cell cycle and circadian cycle}

Various genes involved in cell proliferation are under transcriptional control of the core clock loop, including cell cycle components (cyclin D1, cdc2), regulators of the cell cycle and components of cell cycle checkpoints (weel, mdm2, p21) as well as growth factors (vegf, kitlg) (reviewed in [57, 60]). When circadian gene expression control is disturbed, e.g. in animals carrying clock gene mutations, defects in cell proliferation are observed. For example, in wild type mice, liver cell proliferation in response to partial removal of the liver (partial hepatectomy) is gated to certain times of day. This gating is absent in cryl/2 double mutant animals, leading to reduced efficiency of liver regeneration [61]. Most interestingly, per2 mutants show an increased sensitivity to radiation induced cancer [62]. Furthermore, perl has been implicated in the regulation of the DNA damage checkpoint of the cell cycle and shown to be deregulated in human cancers [63]. In contrast, clock mutant animals do not have any cancer-related phenotype [64], and also cryl/2 double mutant mice do not exhibit a higher tendency to develop cancer [65]. On the contrary, they even show 
reduced cancer incidence in a p53 mutant background [66]. Cells derived from these triple knock-out $\left(\right.$ cryl/cry2/p53 $\left.3^{--}\right)$mice are more sensitive to radiation induced apoptosis and thus die before the induced mutations can lead to oncogenic transformation. Since previous work had shown that DNA damage repair may also be under circadian clock control [67], it was hypothesized that the increased sensitivity to irradiation induced apoptosis was dependent on impaired DNA damage repair. However, the triple mutant cells showed no significant reduction of DNA repair capacity. All these diverse findings indicate that the circadian clock intervenes at various levels in cancer prevention, and that different clock genes might target different aspects of cell proliferation control. In addition, cell proliferation and metabolism are closely intertwined, with proliferating cells and cancer cells showing characteristic changes in metabolic pathways, such as a switch from oxidative phosphorylation to glycolysis (the Warburg effect [68, 69]). One might therefore also expect a contribution of clock regulation of metabolism to the circadian control of cell proliferation [60].

\section{Treating in time: chronotherapy}

The discovery of a clock control of cell proliferation and metabolism has already led to improvements in cancer therapy. So-called "chronotherapeutical" approaches increase the efficiency and reduce side effects of anti-cancer drugs. Cell proliferation rhythms are deregulated in many cancer types [70-72], and so delivering drugs that kill proliferating cells at a time when fewer normal cells divide will preferentially target the cancer cells that have escaped clock control. Another rationale for chronotherapy is linked to the metabolism of xenobiotics (such as cancer drugs): Degradation and modification of these substances is subject to circadian control. Thus, giving a drug at the trough point of degradation activity will allow the 
use of overall lower doses, thereby reducing the potential side effects [72-74]. The beneficial effects of chronotherapeutics have now been demonstrated in various clinical trials (reviewed in [72]).

Central rhythms and cell proliferation: a role for hormones?

As discussed above, there is good evidence that the circadian clock can regulate circadian rhythms of cell proliferation at least partially in a cell-autonomous manner. Nevertheless, a wealth of non-cell-autonomous signals, such as growth factors, nutrients or hormones, also contribute to controlling cell proliferation (see e.g. [7579]), and many of these signals are under circadian clock control [80, 81]. An influence of systemic circadian signals is also indicated by experiments in which tumors were transplanted into animals with SCN ablations: the tumors grew faster in the SCN ablated animals than in normal controls [82]. These systemic signals might interact with peripheral clocks or function independently.

\section{Rhythms of glucocorticoids}

One such systemic signal might be the glucocorticoids, steroid hormones produced by the adrenal gland. They constitute an important part of the stress response and affect numerous physiological processes, such as carbohydrate and lipid metabolism as well as immune system function [83]. They exert their effects on the target tissues via glucocorticoid receptors (GRs). These receptors of the nuclear receptor type reside in the cytoplasm as a complex with heat shock proteins, and translocate to the nucleus when glucocorticoids bind to their ligand binding domain. In the nucleus, they act either by binding to specific DNA sequences, the Glucocorticoid Response Elements (GREs), or via interactions with other transcription factors that do not involve direct DNA binding of the GRs (reviewed in [84]). In both cases they can function as activators or repressors. A second nuclear 
receptor, the mineralocorticoid receptor (MR), binds the endogenous glucocorticoids cortisol and corticosterone with even greater affinity than the glucocorticoid receptor itself (and with a similar affinity as its other natural ligand, the mineralocorticoid aldosterone). It is therefore already activated by the low baseline levels of these glucocorticoids. Aldosterone, which circulates at even lower levels than the glucocorticoids, only becomes its prominent ligand in cells that express the enzyme $11 \beta$-hydoxysteroid dehydrogenase 2 , which converts glucocorticoids to an inactive form (reviewed in [85]). Finally, glucocorticoids may also act via mechanisms that do not involve transcriptional regulation. These so-called non-genomic effects are still poorly understood (reviewed in [86]).

Glucocorticoids have long been recognised to show diurnal rhythms of release (reviewed in [81, 87-89]). In diurnal animals, peak levels of glucocorticoids are encountered in the early morning, whereas nocturnal animals show a peak in the early night. This diurnal rhythm is superimposed on a pulsatile ("ultradian" = shorter than a day) rhythm of release, which consists of 1-2 pulses per hour (Fig 1, A). Similar less robust rhythms, of lower amplitude, are also observed for the adrenocorticotropic hormone ACTH. This peptide hormone, which is produced by the corticotrope cells of the pituitary gland, stimulates adrenal corticosteroid synthesis. Its release in turn is controlled by hypothalamus-derived peptides, the "secretagogues" CRH, AVP and oxytocin, produced by neurons of the paraventricular nucleus (PVN). They are released into the portal blood stream of the median eminence of the pituitary, which transports them to the corticotrope cells in the anterior part of the pituitary. The entire system, linking the hypothalamus with the adrenal gland via the pituitary gland, is referred to as the hypothalamic-pituitary-adrenal (HPA) axis. 
Glucocorticoids also feed back on the HPA axis and their own release, acting through GRs and MRs in the brain (e.g. the hippocampus and the PVN) and the pituitary (reviewed in $[90,91]$ ). Data from mutant mouse models indicate a major role for the GR in this feedback, whereas pharmacological analysis also support an important role for the MR. Feedback sensitivity of the system varies diurnally and appears to involve MR mediated effects at the trough point of the cycle, whereas both MR and GR would mediate feedback at the peak point (see e.g. [92-94]). Based on computer simulations, it has been proposed recently that the glucocorticoid-ACTH feedback loop alone could explain the ultradian pulsatility of glucocorticoid release [95]. According to this model, the delays generated by the transport of ACTH via the blood stream to the adrenal gland and the subsequent inhibition of ACTH release from the pituitary by the rising blood glucocorticoid levels would be sufficient to generate the hourly ultradian pulses. This would exclude the need for an ultradian pacemaker in the brain. This interesting hypothesis awaits testing in vivo.

\section{Central pacemaker control of glucocorticoid rhythms}

Circadian aspects of HPA activity are under control of the SCN (Fig. 2, reviewed in [89]). Thus, lesions of the SCN abolish both glucocorticoid and ACTH rhythms. Only very few projections from the SCN contact the secretagogue-producing neurons of the PVN directly, therefore most of the SCN influence involves indirect connections. These are mediated via interneurons in the PVN itself, but also through relay stations in the subparaventricular zone (subPVZ) and the dorsomedial nucleus of the hypothalamus (DMH) $[96,97]$.

Interestingly, changes in glucocorticoid release do not always appear to be dependent on changes in ACTH levels (reviewed in [98]). Thus, rhythms of 
corticosteroid secretion can still be observed in animals in which the pituitary gland has been removed and which do not show any changing ACTH levels [99, 100]. Furthermore, it was shown that nocturnal light exposure can lead to changes in corticosterone release from the adrenal gland without accompanying changes in ACTH $[101,102]$. This effect of light upon corticosterone release was dependent on the SCN, since ablation of the SCN abolished it. Apparently, in addition to the HPA axis pathway, an alternative neural pathway exists from the SCN to the adrenal gland (Fig.2). Transneural retrograde virus tracing showed that this pathway runs via the autonomic nervous system $[97,101,103]$. SCN neurons contact neurons of the preautonomic PVN, which project to the sympathetic preganglionic neurons of the spinal cord. These neurons in turn innervate the adrenal gland via the splanchnic nerve. Consistent with the functionality of this pathway, denervation of the adrenal gland blocks the light induced corticosterone changes [102]. The splanchnic nerve also seems to mediate changes in the sensitivity of the adrenal gland to ACTH, which modulate corticosterone production and release in a circadian fashion even when ACTH levels do not change (reviewed in [89, 97, 104]).

\section{A clock in the adrenal gland}

Circadian glucocorticoid rhythms are not only controlled by systemic mechanisms. Recent experiments have also revealed a role for the circadian clock present in the adrenal gland in the circadian gating of ACTH sensitivity. Adrenal slice cultures from mice show a stronger response to ACTH stimulation in the evening, at the time of the natural glucocorticoid peak, than in the morning. Furthermore, wildtype adrenal glands transplanted into a host with a non-functional clock are still able to secrete corticosterone in a rhythmic fashion [105]. Finally, tissue specific antisense mediated knock-down of the Bmal1 protein in the adrenal gland abolishes 
circadian glucocorticoid production under constant conditions (however, under a light dark cycle rhythmic production continues, potentially owing to the neural mechanisms mentioned above)[106]. Another facet of circadian regulation of glucocorticoid production seems to involve clock control of gene transcription in the glucocorticoid synthesis pathway, in addition to that of genes participating in the ACTH signalling pathway [105-107].

In summary, a view emerges in which circadian regulation of the HPA axis is not alone in directing circadian glucocorticoid rhythms. Autonomic nervous control mechanisms and the peripheral clock of the adrenal gland itself also appear to contribute substantially to these rhythms. However, ACTH-dependent regulation of glucocorticoid release might be more prominent in acute stress responses [108, 109].

Glucocorticoids talk back to the clock?

Not only does the circadian clock regulate production and release of glucocorticoids, but these also influence the circadian clock itself. Furthermore, glucocorticoids interact with other circadian outputs, one of which is the cell cycle [89].

Glucocorticoids have been implicated in the entrainment of peripheral clocks. This conclusion is based on the observation that injection of the glucocorticoid receptor agonist dexamethasone can phase shift rhythmic gene expression in the liver in vivo. Furthermore, glucocorticoid pulses are able to synchronise clocks in mammalian cell culture cells $[44,110]$. However, mice lacking the glucocorticoid receptor in the liver still exhibit phases of clock gene expression identical to those of their wild type siblings, arguing against a strict requirement for glucocorticoids in liver clock entrainment [44]. Nevertheless, glucocorticoids do appear to be required for normal circadian expression of per2 in some areas of the brain, since cycling 
expression of this gene is abolished in adrenalectomised animals (animals in which the adrenal gland has been removed) $[111,112]$. Interestingly, the per 2 rhythms can resume when diurnal changes in corticosterone are restored in adrenalectomised animals by delivering corticosterone with the drinking water. This is not the case when the animals are supplemented with constant release pellets, indicating that rhythmic glucocorticoid signalling might contribute to rhythm generation [113]. An attenuation of the amplitude (but no effect on the phase) of circadian perl expression has also been reported in livers of the animals with a clock-less adrenal gland mentioned above, whereas rhythmic per2 expression was unaffected [106]. Together, these findings point to the possibility that tissue specific mechanisms might operate in clock gene regulation via glucocorticoids.

While a potential direct contribution of glucocorticoids to peripheral clock entrainment in the liver still remains unclear, glucocorticoids have been shown to modulate another pathway for peripheral clocks: food entrainment. Under daytime restricted feeding, which inverts the feeding habits of nocturnal rodents, peripheral pacemakers become decoupled from the SCN pacemaker. The timing of rhythmic clock gene expression in the periphery adjusts to that of the feeding regime, while the phase of the SCN clock still matches that of the light-dark cycle [41-43]. Glucocorticoids appear to retard the food induced phase shift of peripheral clocks, since phase shifts induced by daytime feeding occur faster in adrenalectomised or GR mutant animals [45]. Precisely how this interaction of food entrainment and glucocorticoids is mediated remains to be established.

Glucocorticoids also interact with transcriptional clock outputs in peripheral tissues. Thus, part of the cycling liver transcriptome is dependent on the adrenal gland [114]. SCN lesions also result in desynchronisation of the circadian liver 
transcriptome, and a single dexamethasone treatment can synchronise about $60 \%$ of this desynchronised gene transcription [115]. The glucocorticoid-sensitive circadian gene HNF4A may in part mediate this synchronisation: The promoter analysis of a subset of the synchronised genes reveals an enrichment of binding sites for HNF4A, together with glucocorticoid response elements (GREs) and E-boxes [115]. This suggests that glucocorticoids may affect circadian transcription at various levels. They may act directly via GREs in target gene promoters, indirectly via glucocorticoid target genes such as HNF4A, via direct effects on clock gene expression and by combinations of these mechanisms. Recent work also implicates clock-glucocorticoid interactions at the protein level: The HAT activity of CLOCK also targets the glucocorticoid receptor, potentially affecting its DNA binding capacity [116].

\section{Glucocorticoids and cell proliferation}

Among the many effects of glucocorticoids on physiology is the regulation of cell proliferation. Glucocorticoids have been described to act both as stimulators and inhibitors of cell proliferation, depending on the cell type and the concentrations used (reviewed in [117]). In general, it appears that a lower concentration of dexamethasone can stimulate cell growth, whereas higher doses inhibit proliferation. In many cell lines, the antiproliferative effects of glucocorticoids seem to stem from a reversible block at the $\mathrm{G} 1$ phase of the cell cycle. Some of the mechanisms proposed for this cell cycle arrest are glucocorticoid mediated repression of cyclin D3 and cmyc, negative crosstalk of the GR with p53, and glucocorticoid mediated induction of the cyclin dependent kinase inhibitors p21 WAF1/CIP1 and p27 kip (reviewed in $[117,118])$. As mentioned above, both p21 and c-myc are also targets of circadian clock control, thus providing potential candidates for a direct cross talk of circadian clock regulation with glucocorticoid signalling. 
The effects of glucocorticoids upon cell proliferation are also revealed in animals that are deficient for glucocorticoids or glucocorticoid signalling. Interestingly, cell proliferation appears disturbed only in a rather limited set of tissues (Table 1). Adrenalectomy has been reported to result in reduced cell proliferation, for example in the small intestine [119-121], and in increased proliferation in regions of the brain $([122,123]$ and see the section on neurogenesis below). Also lung cell proliferation is influenced by glucocorticoids, as revealed by studies of mice lacking the CRH peptide $[124,125]$. These mice show glucocorticoid deficiency, but develop normally and are fertile. However, homozygous mutant pups which are the offspring of homozygous mutant mothers die from pulmonary insufficiency. This mortality is at least partially caused by continued lung cell proliferation during gestation and an overall delay in pulmonary maturation.

\section{Cell proliferation defects in glucocorticoid receptor mutants}

Interestingly, mice in which the glucocorticoid receptor has been disrupted die due to defects in lung function (atelactasis = collapse of lung tissue) shortly after birth. Other defects seen in these mice include impaired maturation of the skin, reduced gluconeogenic gene expression in the liver, a lack of in vitro T cell apoptosis and upregulation of POMC expression [126, 127]. However, no major tissue defects due to impaired cell proliferation are observed, suggesting that the GR is not strictly required for the regulation of cell proliferation during development in many tissues. Nevertheless, certain tissues are significantly affected. Thus, the lack of glucocorticoid receptor function abolishes stress induced (but not normal) erythropoiesis in vivo, as shown by transplantation studies using erythroid progenitor 
cells derived from $\mathrm{GR}^{-/-}$fetal livers [128]. Stress erythropoiesis appears to require binding of the receptor to DNA, since stress induced proliferation is also severely impaired in mice carrying a receptor dimerisation mutant $\left(\mathrm{GR}^{\mathrm{dim} / \mathrm{dim}}\right)$. In these mutants, the GR gene has been engineered to disrupt a residue required for dimerisation and hence the binding to GRE elements, but which still allows the GR to interact with other transcription factors [129].

Interestingly, the impaired maturation of the skin observed in $\mathrm{GR}^{-/-}$mice, resulting in compromised skin barrier competence, can be linked to a defective switch between differentiation and proliferation. Although overall proliferation in the epidermis is not increased, abnormally proliferating suprabasal keratinocytes are observed in these fetuses. Additionally, primary keratinocytes from $\mathrm{GR}^{-/-}$animals show an increased proliferation rate in culture compared to wild type cells. This indicates that the GR participates in the decision between proliferation and differentiation in a cell autonomous manner [130]. In contrast to what was seen in the case of stress erythropoiesis, this role seems to be independent of the DNA binding of the GR $[130,131]$.

\section{Glucocorticoids and neurogenesis}

Another proliferative process affected by loss of glucocorticoids is neurogenesis (Table 2). Adrenalectomy leads to an increase in proliferation of the granule cells of the dentate gyrus in the hippocampus, one of the regions of adult neurogenesis $[132$, 133]. Conversely, treatment with exogenous corticosterone inhibits granule cell proliferation [133]. Therefore, it has been proposed that glucocorticoids might at least in part mediate the decrease of neurogenesis observed in the dentate gyrus under stress conditions, during which glucocorticoids are elevated (reviewed in [134], see 
also [135] for a review of recent studies supporting mechanisms independent of glucocorticoids).

Adrenalectomy also leads to an increase in granule cell death, suggesting that while proliferation increases, survival of the cells decreases [136, 137]. The cell death can be rescued by adding corticosterone to the drinking water [137]. Importantly, treatment with aldosterone, which activates the MR but not the GR, can also prevent adrenalectomy induced cell death, implicating a protective role for this receptor [138]. Conversely, activation of the GR using its specific agonist dexamethasone does not rescue this cell death $[139,140]$. Interestingly, in intact animals, glucocorticoid receptor agonists can induce apoptosis in granule cells, and mineralocorticoid receptor activation can protect against this effect $[141,142]$. It thus appears that a balance between MR and GR activation, affecting both cell proliferation and survival, is required for normal neurogenesis in the dentate gyrus.

Examination of mutant mice lacking MRs or GRs in the brain has brought additional insight into the role of these two receptors in neurogenesis. Mice completely lacking the MR can be rescued from death by renal salt and water loss via exogenous $\mathrm{NaCl}$ administration and thereby can be studied as adults. These mice show granule cell degeneration similar to that observed with adrenalectomy. Apparently paradoxically however, the number of proliferating granule cells is reduced in MR knock-out mice, in contrast to the increase observed upon adrenalectomy. One potential explanation for this comes from the increased plasma levels of corticosterone in the MR knock-out mice, which might potentially inhibit proliferation via the GR. Importantly, no degeneration is observed in mice with a nervous system specific GR knock-out (driven by nestin regulatory elements [143]), reinforcing the notion of a MR dependent cell death protection mechanism [144]. 
Interestingly however, mice with a brain specific MR knock-out (driven by CAMKII $\alpha$ regulatory elements) do not exhibit the increased glucocorticoid levels observed in the mice completely lacking the MR, and also they do not show conspicuous changes in cell number and density in the dentate gyrus of the hippocampus [145]. Thus, the emerging picture of how glucocorticoids regulate neurogenesis is complex and may involve mechanisms combining the direct and indirect effects of both GR and MR.

\section{Neurogenesis and circadian rhythms - are glucocorticoids involved?}

Interestingly, some recent studies implicate a role for the circadian changes of glucocorticoid levels in hippocampal neurogenesis. Thus, artificially dampening the circadian corticosterone rhythm prevents fluoxetine, a serotonin uptake inhibitor, from stimulating neurogenesis. Restoring the corticosterone rhythm also restores the action of fluoxetine [146]. Similar results were obtained with L-NAME, a nitric oxide synthase (NOS) inhibitor that also stimulates hippocampal neurogenesis [147, 148]. Thus, it appears that the circadian rhythm of glucocorticoids interacts with other signalling pathways in regulating neurogenesis. It remains to be seen to what extent these interactions contribute to normal neurogenesis.

Do the highly dynamic changes in glucocorticoid levels, together with the associated differential GR and MR signalling activity, contribute to the timing of proliferation and apoptosis? It appears that the lower glucocorticoid affinity of the GR, together with the rapid clearance of the activated receptor by a proteasomedependent mechanism, leads to a signalling activity that closely follows changes in glucocorticoid levels. In contrast, the high affinity MR already responds to low glucocorticoid levels and its signalling activity appears to be more sustained (reviewed in [88]). These dynamics have consequences for gene expression: For the 
GR, it has been shown that pulsatile glucocorticoid signals can lead to different induction levels and expression dynamics of GR target genes compared with those observed under continuous stimulation [149]. It will be interesting to examine links between the circadian and ultradian changes in glucocorticoid levels, the different dynamic signalling properties of GR and MR, as well as the regulation of cell proliferation and survival.

If the daily dynamics of glucocorticoids are important in the regulation of proliferation, they might at least in part exert their effect by regulating circadian rhythms of cell proliferation. However, in the case of hippocampal neurogenesis, while some studies did observe diurnal rhythms of granule cell layer proliferation in the dentate gyrus, several other studies failed to detect such rhythms ([150-153], reviewed in [135]). Thus, the effects of glucocorticoids on neurogenesis might not involve changes in rhythmic cell proliferation per se. Interestingly, expression of the clock gene per2 does not show circadian regulation in the adult dentate gyrus [154]. Furthermore, per 2 mutant animals show a higher number of neural progenitor cells and newborn neurons, but also increased apoptosis. These observations may in part be related to the dampened glucocorticoid rhythms also observed in these animals [155]. However, in vitro studies also suggest that per2 exerts more direct effects on neural progenitors [154], which seem to be independent of its role in circadian clock regulation. Thus, the precise links between the circadian clock mechanism, glucocorticoid dynamics and neurogenesis remain unclear.

\section{Glucocorticoids and rhythms of cell proliferation}

In contrast to the hippocampus, cell proliferation rhythms have been described in other tissues in which proliferation is also affected by glucocorticoids, (e. g. blood and bone marrow [156], gastrointestinal mucosa [157], and skin [157, 158]). Some 
early reports also suggested changes in these rhythms upon manipulation of glucocorticoids, e.g. in the cornea epithelium [159] or during liver regeneration [160]. However, much of the data presented has limitations, and so for example, the effects of the treatments upon the circadian clock itself were frequently not examined.

Our own studies have revealed a role for glucocorticoids in the regulation of circadian rhythms of cell proliferation in zebrafish larvae [161]. Circadian cell cycle rhythms can be observed both in larvae and in zebrafish-derived cell lines, implying that cell-autonomous clock regulation also exists in this species [162]. However, in vivo, systemic input is also required: in mutants lacking a pituitary gland, cell cycle rhythms are severely attenuated [161]. Subsequent analysis of mutants that lack subsets of the pituitary cell types identified the corticotrope lineage as the source for the required signal. Thus, larvae homozygous for a truncated allele of the homeobox transcription factor $r x 3$ [163], which possess reduced numbers of corticotrope cells, have severely attenuated cell cycle rhythms. In contrast, pitl mutants [164], which lack the somatotrope, thyrotrope and lactotrope lineages but still possess gonadotrope, melanotrope and corticotrope cells, show rhythms indistinguishable from their wildtype siblings. As a consequence of their strongly reduced corticotrope cell number, $r x 3$ mutants contain lower cortisol levels than wildtype larvae, and also the diurnal cortisol changes observed in the wildtype siblings are not present. Interestingly, overall clock gene rhythms in these animals are unchanged, excluding a dominant role for glucocorticoids in peripheral clock synchronisation. Importantly, normal cell cycle rhythms can be rescued in the $r x 3$ mutants by tonic treatment with dexamethasone. Hence, glucocorticoids cooperate with the peripheral circadian clock in the regulation of circadian cell cycle rhythms. They might act as permissive signals that enable the peripheral clocks to control the cell cycle, or alternatively the 
peripheral clocks might gate glucocorticoid input into the cell cycle machinery. The dexamethasone rescue experiments indicate that circadian changes of glucocorticoid levels are not required for their action on the circadian cell cycle rhythms. However, cycling glucocorticoid levels may still contribute by ensuring correct signalling input to the cell cycle machinery. It will be of great interest to determine whether similar interactions between peripheral clocks and systemic signals regulate circadian rhythms of cell proliferation in the mammalian system, e.g. those observed in liver regeneration after partial hepatectomy [61].

The interaction of glucocorticoid and circadian clock control of cell proliferation may not be limited to one single mechanism, given the diverse effects of glucocorticoids on cell proliferation in different tissues. As mentioned above, a similar situation exists for the contribution of glucocorticoids to circadian clock gene cycling in different tissues: While circadian per 2 expression in some regions of the brain depends on glucocorticoids $[111,112]$, this is not the case in other brain regions [112] or the liver [44, 114]. Clearly, similar tissue specific differences might also be at work in the control of circadian cell cycle rhythms by glucocorticoids, with rhythmic glucocorticoid presence required in some tissues and tonic levels being sufficient in others.

\section{Timing of glucocorticoids - potential in cancer therapy?}

Glucocorticoid mediated induction of apoptosis and cell cycle arrest have long been exploited for therapy (reviewed in $[117,165,166])$. Thus, the glucocorticoid mediated induction of apoptosis in the blood cell lineage is exploited for the treatment of leukaemia. On the other hand, glucocorticoids can also confer resistance to apoptosis induced by various other stimuli. This is the case for example in cells of epithelial origin (e.g. cells of the mammary gland or lung epithelial cells, see [167]) 
and in solid malignant tumours $[168,169]$. Interestingly, the anti-proliferative effect of glucocorticoids mentioned above might also negatively influence cancer therapy. The pretreatment of patients with glucocorticoids to alleviate nausea or to treat tumour-associated oedema and inflammatory responses can lead to cell cycle arrest in the G1 phase. Thus, in glucocorticoid sensitive tumours, therapy can be negatively affected, because non-proliferating cells are less vulnerable to chemotherapy. Also radiotherapy can be impaired by the G1 arrest, since the sensitivity of cells to radiotherapy is highest at $\mathrm{M}$ phase [117]. In this scenario a chronotherapeutic approach might prove particulary useful: One could administer glucocorticoids and chemo- or radiotherapy with a distinct time profile that would retain at least some of the beneficial effects of glucocorticoids while avoiding their effects on the cell cycle at the time of therapy. Conversely, arresting normal cell proliferation via glucocorticoids might allow chemo- or radiotherapy of glucocorticoid resistant tumors with less toxic side effects. Glucocorticoid chronotherapy has already been employed successfully to treat rheumatoid arthritis and asthma [170, 171]. Importantly, glucocorticoid rhythms are deregulated in many cancer patients [172] and have been correlated with survival [173]. Thus, a better understanding of the molecular mechanisms underlying the involvement of glucocorticoids in the control of cell cycle timing should also ultimately help to design more efficient treatment schemes in cancer therapy.

\section{Where are we heading?}

This survey illustrates the impressive diversity of effects that glucocorticoid hormones have upon cell proliferation. Depending on the cell type and tissue, they can either promote or inhibit cell proliferation, and they do this by targeting different aspects of tissue homeostasis. Thus, they influence proliferation itself, but are also involved in 
switches between differentiation and proliferation, and they can regulate cell death and survival. Their effects can be systemic or local, direct or indirect, and involve cross talk with other signalling pathways. Glucocorticoid signalling can require DNA binding of the glucocorticoid receptors, or involve DNA-binding independent interactions with other transcription factors. Importantly, the signalling outcome can also depend on the balanced activation of the two main types of glucocorticoid receptors, GR and MR. Clearly, one major goal for future research will be to better understand the precise mechanisms underlying the glucocorticoid control of cell proliferation in various tissues and to convert this knowledge into more efficient therapies.

One major unexplored area is how the dynamic changes of glucocorticoid ligand concentrations translate into signalling activity and how this affects the temporal regulation of gene expression. This fundamental question is of direct relevance for all cell signalling pathways. The glucocorticoid pathway promises to be a particularly attractive model system to study such temporal aspects of signal transduction in both the cellular and systemic context, given the characteristic circadian and ultradian rhythms of glucocorticoid release. The circadian clock represents probably the best understood biological timing system from the physiological to the molecular level. One of its regulatory targets is the cell cycle, which constitutes yet another cellular timing system. Thus, links between the circadian clock and glucocorticoid control of cell proliferation form an ideal framework in which to examine the temporal integration of signalling pathways and of their physiological output. Future research in this field will need to develop experimental tools to specifically manipulate the dynamics of glucocorticoid signalling. In the long term, knowledge gained from such 
studies should pave the way towards novel, more specific therapeutic strategies entailing fewer harmful side effects.

\section{Acknowledgements}

We thank Meltem Sahinbas and Benjamin Weger for a critical reading of the manuscript and help with figure preparation.

\section{References}

1. Dunlap, J., J. Loros, and P. DeCoursey, Chronobiology. 2004, Sunderland: Sinauer Associates.

2. Klein, D.C., R.Y. Moore, and S.M. Reppert, Suprachiasmatic Nucleus - The Mind's Clock. 1991, New York: Oxford University Press.

3. Ralph, M.R., et al., Transplanted suprachiasmatic nucleus determines circadian period. Science, 1990. 247(4945): p. 975-8.

4. Ralph, M.R. and M. Menaker, A mutation of the circadian system in golden hamsters. Science, 1988. 241(4870): p. 1225-7.

5. Silver, R., et al., A diffusible coupling signal from the transplanted suprachiasmatic nucleus controlling circadian locomotor rhythms. Nature, 1996. 382(6594): p. 810-3.

6. Meyer-Bernstein, E.L., et al., Effects of suprachiasmatic transplants on circadian rhythms of neuroendocrine function in golden hamsters. Endocrinology, 1999. 140(1): p. 207-18.

7. Antle, M.C., et al., Physiological responses of the circadian clock to acute light exposure at night. Rev Endocr Metab Disord, 2009.

8. Bailes, H.J. and R.J. Lucas, Melanopsin and inner retinal photoreception. Cell Mol Life Sci, 2009.

9. Paul, K.N., T.B. Saafir, and G. Tosini, The role of retinal photoreceptors in the regulation of circadian rhythms. Rev Endocr Metab Disord, 2009.

10. Guler, A.D., et al., Melanopsin cells are the principal conduits for rod-cone input to non-image-forming vision. Nature, 2008. 453(7191): p. 102-5.

11. Panda, S., et al., Melanopsin is required for non-image-forming photic responses in blind mice. Science, 2003. 301(5632): p. 525-7.

12. Zaidi, F.H., et al., Short-wavelength light sensitivity of circadian, pupillary, and visual awareness in humans lacking an outer retina. Curr Biol, 2007. 17(24): p. 2122-8.

13. Herzog, E.D., et al., Circadian rhythms in mouse suprachiasmatic nucleus explants on multimicroelectrode plates. Brain Res, 1997. 757(2): p. 285-90.

14. Welsh, D.K., et al., Individual neurons dissociated from rat suprachiasmatic nucleus express independently phased circadian firing rhythms. Neuron, 1995. 14(4): p. 697-706. 
15. Dong, G. and S.S. Golden, How a cyanobacterium tells time. Curr Opin Microbiol, 2008. 11(6): p. 541-6.

16. Hastings, J.W., The Gonyaulax clock at 50: translational control of circadian expression. Cold Spring Harb Symp Quant Biol, 2007. 72: p. 141-4.

17. Lakin-Thomas, P.L., New models for circadian systems in microorganisms. FEMS Microbiol Lett, 2006. 259(1): p. 1-6.

18. Ko, C.H. and J.S. Takahashi, Molecular components of the mammalian circadian clock. Hum Mol Genet, 2006. 15 Spec No 2: p. R271-7.

19. Gallego, M. and D.M. Virshup, Post-translational modifications regulate the ticking of the circadian clock. Nat Rev Mol Cell Biol, 2007. 8(2): p. 139-48.

20. Lowrey, P.L., et al., Positional syntenic cloning and functional characterization of the mammalian circadian mutation tau. Science, 2000. 288(5465): p. 483-92.

21. Xu, Y., et al., Functional consequences of a CKIdelta mutation causing familial advanced sleep phase syndrome. Nature, 2005. 434(7033): p. 640-4.

22. Meng, Q.J., et al., Setting clock speed in mammals: the CK1 epsilon tau mutation in mice accelerates circadian pacemakers by selectively destabilizing PERIOD proteins. Neuron, 2008. 58(1): p. 78-88.

23. Maier, B., et al., A large-scale functional RNAi screen reveals a role for CK2 in the mammalian circadian clock. Genes Dev, 2009. 23(6): p. 708-18.

24. Lamia, K.A., et al., AMPK regulates the circadian clock by cryptochrome phosphorylation and degradation. Science, 2009. 326(5951): p. 437-40.

25. Busino, L., et al., SCFFbxl3 controls the oscillation of the circadian clock by directing the degradation of cryptochrome proteins. Science, 2007.

316(5826): p. 900-4.

26. Godinho, S.I., et al., The after-hours mutant reveals a role for Fbxl3 in determining mammalian circadian period. Science, 2007. 316(5826): p. 897900.

27. Siepka, S.M., et al., Circadian mutant Overtime reveals F-box protein FBXL3 regulation of cryptochrome and period gene expression. Cell, 2007. 129(5): p. 1011-23.

28. Hirayama, J., et al., CLOCK-mediated acetylation of BMAL1 controls circadian function. Nature, 2007. 450(7172): p. 1086-90.

29. Asher, G., et al., SIRT1 regulates circadian clock gene expression through PER2 deacetylation. Cell, 2008. 134(2): p. 317-28.

30. Duez, H. and B. Staels, The nuclear receptors Rev-erbs and RORs integrate circadian rhythms and metabolism. Diab Vasc Dis Res, 2008. 5(2): p. 82-8.

31. Balsalobre, A., Clock genes in mammalian peripheral tissues. Cell Tissue Res, 2002. 309(1): p. 193-9.

32. Andrews, R.V., Circadian rhythms in adrenal organ cultures. Gegenbaurs Morphol Jahrb, 1971. 117(1): p. 89-98.

33. Whitmore, D., et al., Zebrafish Clock rhythmic expression reveals independent peripheral circadian oscillators. Nat Neurosci, 1998. 1(8): p. 701-7.

34. Yamazaki, S., et al., Resetting central and peripheral circadian oscillators in transgenic rats. Science, 2000. 288(5466): p. 682-5.

35. Yoo, S.H., et al., PERIOD2::LUCIFERASE real-time reporting of circadian dynamics reveals persistent circadian oscillations in mouse peripheral tissues. Proc Natl Acad Sci U S A, 2004. 101(15): p. 5339-46. 
36. Kaneko, M., N. Hernandez-Borsetti, and G.M. Cahill, Diversity of zebrafish peripheral oscillators revealed by luciferase reporting. Proc Natl Acad Sci U S A, 2006. 103(39): p. 14614-9.

37. Nagoshi, E., et al., Circadian gene expression in individual fibroblasts: cellautonomous and self-sustained oscillators pass time to daughter cells. Cell, 2004. 119(5): p. 693-705.

38. Welsh, D.K., et al., Bioluminescence imaging of individual fibroblasts reveals persistent, independently phased circadian rhythms of clock gene expression. Curr Biol, 2004. 14(24): p. 2289-95.

39. Carr, A.J. and D. Whitmore, Imaging of single light-responsive clock cells reveals fluctuating free-running periods. Nat Cell Biol, 2005. 7(3): p. 319-21.

40. Brown, S.A., et al., Rhythms of mammalian body temperature can sustain peripheral circadian clocks. Curr Biol, 2002. 12(18): p. 1574-83.

41. Damiola, F., et al., Restricted feeding uncouples circadian oscillators in peripheral tissues from the central pacemaker in the suprachiasmatic nucleus. Genes Dev, 2000. 14(23): p. 2950-61.

42. Hara, R., et al., Restricted feeding entrains liver clock without participation of the suprachiasmatic nucleus. Genes Cells, 2001. 6(3): p. 269-78.

43. Stokkan, K.A., et al., Entrainment of the circadian clock in the liver by feeding. Science, 2001. 291(5503): p. 490-3.

44. Balsalobre, A., et al., Resetting of circadian time in peripheral tissues by glucocorticoid signaling. Science, 2000. 289(5488): p. 2344-7.

45. Le Minh, N., et al., Glucocorticoid hormones inhibit food-induced phaseshifting of peripheral circadian oscillators. Embo J, 2001. 20(24): p. 7128-36.

46. Lamia, K.A., K.F. Storch, and C.J. Weitz, Physiological significance of a peripheral tissue circadian clock. Proc Natl Acad Sci U S A, 2008. 105(39): p. 15172-7.

47. Kornmann, B., et al., System-driven and oscillator-dependent circadian transcription in mice with a conditionally active liver clock. PLoS Biol, 2007. 5(2): p. e34.

48. Kalsbeek, A., et al., Circadian control of the daily plasma glucose rhythm: an interplay of GABA and glutamate. PLoS ONE, 2008. 3(9): p. e3194.

49. Panda, S., et al., Coordinated transcription of key pathways in the mouse by the circadian clock. Cell, 2002. 109(3): p. 307-20.

50. Turek, F.W., et al., Obesity and metabolic syndrome in circadian Clock mutant mice. Science, 2005. 308(5724): p. 1043-5.

51. Nakahata, Y., et al., The NAD+-dependent deacetylase SIRT1 modulates CLOCK-mediated chromatin remodeling and circadian control. Cell, 2008. 134(2): p. 329-40.

52. Nakahata, Y., et al., Circadian control of the NAD+ salvage pathway by CLOCK-SIRT1. Science, 2009. 324(5927): p. 654-7.

53. Ramsey, K.M., et al., Circadian clock feedback cycle through NAMPTmediated NAD+ biosynthesis. Science, 2009. 324(5927): p. 651-4.

54. Bjarnason, G.A. and R. Jordan, Circadian variation of cell proliferation and cell cycle protein expression in man: clinical implications. Prog Cell Cycle Res, 2000. 4: p. 193-206.

55. Mori, T. and C.H. Johnson, Circadian control of cell division in unicellular organisms. Prog Cell Cycle Res, 2000. 4: p. 185-92.

56. Reddy, A.B., et al., Circadian clocks: neural and peripheral pacemakers that impact upon the cell division cycle. Mutat Res, 2005. 574(1-2): p. 76-91. 
57. Borgs, L., et al., Cell "circadian" cycle: new role for mammalian core clock genes. Cell Cycle, 2009. 8(6): p. 832-7.

58. Nikaido, S.S. and C.H. Johnson, Daily and circadian variation in survival from ultraviolet radiation in Chlamydomonas reinhardtii. Photochem Photobiol, 2000. 71(6): p. 758-65.

59. Pittendrigh, C.S., Temporal organization: reflections of a Darwinian clockwatcher. Annu Rev Physiol, 1993. 55: p. 16-54.

60. Sahar, S. and P. Sassone-Corsi, Metabolism and cancer: the circadian clock connection. Nat Rev Cancer, 2009. 9(12): p. 886-96.

61. Matsuo, T., et al., Control mechanism of the circadian clock for timing of cell division in vivo. Science, 2003. 302(5643): p. 255-9.

62. Fu, L., et al., The circadian gene Period2 plays an important role in tumor suppression and DNA damage response in vivo. Cell, 2002. 111(1): p. 41-50.

63. Gery, S., et al., The circadian gene per1 plays an important role in cell growth and DNA damage control in human cancer cells. Mol Cell, 2006. 22(3): p. 375-82.

64. Antoch, M.P., et al., Disruption of the circadian clock due to the Clock mutation has discrete effects on aging and carcinogenesis. Cell Cycle, 2008. 7(9): p. 1197-204.

65. Gauger, M.A. and A. Sancar, Cryptochrome, circadian cycle, cell cycle checkpoints, and cancer. Cancer Res, 2005. 65(15): p. 6828-34.

66. Ozturk, N., et al., Loss of cryptochrome reduces cancer risk in p53 mutant mice. Proc Natl Acad Sci U S A, 2009. 106(8): p. 2841-6.

67. Kang, T.H., et al., Circadian oscillation of nucleotide excision repair in mammalian brain. Proc Natl Acad Sci U S A, 2009. 106(8): p. 2864-7.

68. DeBerardinis, R.J., et al., The biology of cancer: metabolic reprogramming fuels cell growth and proliferation. Cell Metab, 2008. 7(1): p. 11-20.

69. Vander Heiden, M.G., L.C. Cantley, and C.B. Thompson, Understanding the Warburg effect: the metabolic requirements of cell proliferation. Science, 2009. 324(5930): p. 1029-33.

70. Canaple, L., T. Kakizawa, and V. Laudet, The days and nights of cancer cells. Cancer Res, 2003. 63(22): p. 7545-52.

71. Levi, F., et al., Implications of circadian clocks for the rhythmic delivery of cancer therapeutics. Adv Drug Deliv Rev, 2007. 59(9-10): p. 1015-35.

72. Levi, F., et al., Circadian timing in cancer treatments. Annu Rev Pharmacol Toxicol. 50: p. 377-421.

73. Levi, F. and U. Schibler, Circadian rhythms: mechanisms and therapeutic implications. Annu Rev Pharmacol Toxicol, 2007. 47: p. 593-628.

74. Levi, F., Chronotherapeutics: the relevance of timing in cancer therapy. Cancer Causes Control, 2006. 17(4): p. 611-21.

75. Dechant, R. and M. Peter, Nutrient signals driving cell growth. Curr Opin Cell Biol, 2008. 20(6): p. 678-87.

76. Puzianowska-Kuznicka, M., et al., Thyroid hormones and their receptors in the regulation of cell proliferation. Acta Biochim Pol, 2006. 53(4): p. 641-50.

77. Nilsson, O., et al., Endocrine regulation of the growth plate. Horm Res, 2005. 64(4): p. 157-65.

78. Pollak, M., Insulin and insulin-like growth factor signalling in neoplasia. Nat Rev Cancer, 2008. 8(12): p. 915-28.

79. Ulloa, F. and J. Briscoe, Morphogens and the control of cell proliferation and patterning in the spinal cord. Cell Cycle, 2007. 6(21): p. 2640-9. 
80. Hastings, M., J.S. O'Neill, and E.S. Maywood, Circadian clocks: regulators of endocrine and metabolic rhythms. J Endocrinol, 2007. 195(2): p. 187-98.

81. Haus, E., Chronobiology in the endocrine system. Adv Drug Deliv Rev, 2007. 59(9-10): p. 985-1014.

82. Filipski, E., et al., Host circadian clock as a control point in tumor progression. J Natl Cancer Inst, 2002. 94(9): p. 690-7.

83. Norris, D.O., Vertebrate Endocrinology. edn 4 ed. 2007, Burlington, San Diego, London: Elsevier Academic Press.

84. Kassel, O. and P. Herrlich, Crosstalk between the glucocorticoid receptor and other transcription factors: molecular aspects. Mol Cell Endocrinol, 2007. 275(1-2): p. 13-29.

85. Joels, M., et al., The coming out of the brain mineralocorticoid receptor. Trends Neurosci, 2008. 31(1): p. 1-7.

86. Haller, J., E. Mikics, and G.B. Makara, The effects of non-genomic glucocorticoid mechanisms on bodily functions and the central neural system. A critical evaluation of findings. Front Neuroendocrinol, 2008. 29(2): p. 27391.

87. Chrousos, G.P., Ultradian, circadian, and stress-related hypothalamicpituitary-adrenal axis activity--a dynamic digital-to-analog modulation. Endocrinology, 1998. 139(2): p. 437-40.

88. Lightman, S.L., et al., The significance of glucocorticoid pulsatility. Eur J Pharmacol, 2008. 583(2-3): p. 255-62.

89. Dickmeis, T., Glucocorticoids and the circadian clock. J Endocrinol, 2009. 200(1): p. 3-22.

90. Jacobson, L., Hypothalamic-pituitary-adrenocortical axis regulation. Endocrinol Metab Clin North Am, 2005. 34(2): p. 271-92, vii.

91. Kolber, B.J., L. Wieczorek, and L.J. Muglia, Hypothalamic-pituitary-adrenal axis dysregulation and behavioral analysis of mouse mutants with altered glucocorticoid or mineralocorticoid receptor function. Stress, 2008. 11(5): p. 321-38.

92. Ratka, A., et al., On the role of brain mineralocorticoid (type I) and glucocorticoid (type II) receptors in neuroendocrine regulation.

Neuroendocrinology, 1989. 50(2): p. 117-23.

93. Spencer, R.L., et al., Evidence for mineralocorticoid receptor facilitation of glucocorticoid receptor-dependent regulation of hypothalamic-pituitaryadrenal axis activity. Endocrinology, 1998. 139(6): p. 2718-26.

94. Young, E.A., et al., The role of mineralocorticoid receptors in hypothalamicpituitary-adrenal axis regulation in humans. J Clin Endocrinol Metab, 1998. 83(9): p. 3339-45.

95. Walker, J.J., J.R. Terry, and S.L. Lightman, Origin of ultradian pulsatility in the hypothalamic-pituitary-adrenal axis. Proc Biol Sci, 2010. 277(1688): p. 1627-33.

96. Buijs, R.M., et al., The biological clock tunes the organs of the body: timing by hormones and the autonomic nervous system. J Endocrinol, 2003. 177(1): p. 17-26.

97. Engeland, W.C. and M.M. Arnhold, Neural circuitry in the regulation of adrenal corticosterone rhythmicity. Endocrine, 2005. 28(3): p. 325-32.

98. Bornstein, S.R., et al., Dissociation of ACTH and glucocorticoids. Trends Endocrinol Metab, 2008. 19(5): p. 175-80. 
99. Meier, A.H., Daily variation in concentration of plasma corticosteroid in hypophysectomized rats. Endocrinology, 1976. 98(6): p. 1475-9.

100. Srivastava, A.K. and A.H. Meier, Daily variation in concentration of cortisol in plasma in intact and hypophysectomized gulf killifish. Science, 1972. 177(44): p. 185-7.

101. Buijs, R.M., et al., Anatomical and functional demonstration of a multisynaptic suprachiasmatic nucleus adrenal (cortex) pathway. Eur J Neurosci, 1999. 11(5): p. 1535-44.

102. Ishida, A., et al., Light activates the adrenal gland: timing of gene expression and glucocorticoid release. Cell Metab, 2005. 2(5): p. 297-307.

103. Ueyama, T., et al., Suprachiasmatic nucleus: a central autonomic clock. Nat Neurosci, 1999. 2(12): p. 1051-3.

104. Ulrich-Lai, Y.M., M.M. Arnhold, and W.C. Engeland, Adrenal splanchnic innervation contributes to the diurnal rhythm of plasma corticosterone in rats by modulating adrenal sensitivity to ACTH. Am J Physiol Regul Integr Comp Physiol, 2006. 290(4): p. R1128-35.

105. Oster, H., et al., The circadian rhythm of glucocorticoids is regulated by a gating mechanism residing in the adrenal cortical clock. Cell Metab, 2006. 4(2): p. 163-73.

106. Son, G.H., et al., Adrenal peripheral clock controls the autonomous circadian rhythm of glucocorticoid by causing rhythmic steroid production. Proc Natl Acad Sci U S A, 2008. 105(52): p. 20970-5.

107. Oster, H., et al., Transcriptional profiling in the adrenal gland reveals circadian regulation of hormone biosynthesis genes and nucleosome assembly genes. J Biol Rhythms, 2006. 21(5): p. 350-61.

108. Kalsbeek, A., et al., The diurnal modulation of hormonal responses in the rat varies with different stimuli. J Neuroendocrinol, 2003. 15(12): p. 1144-55.

109. Kalsbeek, A., et al., A diurnal rhythm of stimulatory input to the hypothalamopituitary-adrenal system as revealed by timed intrahypothalamic administration of the vasopressin V1 antagonist. J Neurosci, 1996. 16(17): p. 5555-65.

110. Balsalobre, A., F. Damiola, and U. Schibler, A serum shock induces circadian gene expression in mammalian tissue culture cells. Cell, 1998. 93(6): p. 92937.

111. Amir, S., et al., A circadian rhythm in the expression of PERIOD2 protein reveals a novel SCN-controlled oscillator in the oval nucleus of the bed nucleus of the stria terminalis. J Neurosci, 2004. 24(4): p. 781-90.

112. Lamont, E.W., et al., The central and basolateral nuclei of the amygdala exhibit opposite diurnal rhythms of expression of the clock protein Period2. Proc Natl Acad Sci U S A, 2005. 102(11): p. 4180-4.

113. Segall, L.A., et al., Glucocorticoid rhythms control the rhythm of expression of the clock protein, Period2, in oval nucleus of the bed nucleus of the stria terminalis and central nucleus of the amygdala in rats. Neuroscience, 2006. 140(3): p. 753-7.

114. Oishi, K., et al., Genome-wide expression analysis reveals 100 adrenal glanddependent circadian genes in the mouse liver. DNA Res, 2005. 12(3): p. 191202.

115. Reddy, A.B., et al., Glucocorticoid signaling synchronizes the liver circadian transcriptome. Hepatology, 2007. 45(6): p. 1478-88. 
116. Nader, N., G.P. Chrousos, and T. Kino, Circadian rhythm transcription factor CLOCK regulates the transcriptional activity of the glucocorticoid receptor by acetylating its hinge region lysine cluster: potential physiological implications. FASEB J, 2009. 23(5): p. 1572-83.

117. Mattern, J., M.W. Buchler, and I. Herr, Cell cycle arrest by glucocorticoids may protect normal tissue and solid tumors from cancer therapy. Cancer Biol Ther, 2007. 6(9): p. 1345-54.

118. Chebotaev, D., A. Yemelyanov, and I. Budunova, The mechanisms of tumor suppressor effect of glucocorticoid receptor in skin. Mol Carcinog, 2007. 46(8): p. 732-40.

119. Tutton, P.J., Proliferation of epithelial cells in the jejunal crypts of adrenalectomized and adrenocortical hormone treated rats. Virchows Arch B Cell Pathol, 1973. 13(3): p. 227-32.

120. Foligne, B., et al., Changes in cell proliferation and differentiation of adult rat small intestine epithelium after adrenalectomy: kinetic, biochemical, and morphological studies. Dig Dis Sci, 2001. 46(6): p. 1236-46.

121. Miyata, T., Y. Minai, and M. Haga, Impaired growth of small intestinal epithelium by adrenalectomy in weaning rats. Acta Histochem Cytochem, 2008. 41(4): p. 83-8.

122. Yehuda, R., K.R. Fairman, and J.S. Meyer, Enhanced brain cell proliferation following early adrenalectomy in rats. J Neurochem, 1989. 53(1): p. 241-8.

123. Alonso, G., Prolonged corticosterone treatment of adult rats inhibits the proliferation of oligodendrocyte progenitors present throughout white and gray matter regions of the brain. Glia, 2000. 31(3): p. 219-31.

124. Muglia, L., et al., Corticotropin-releasing hormone deficiency reveals major fetal but not adult glucocorticoid need. Nature, 1995. 373(6513): p. 427-32.

125. Muglia, L.J., et al., Proliferation and differentiation defects during lung development in corticotropin-releasing hormone-deficient mice. Am J Respir Cell Mol Biol, 1999. 20(2): p. 181-8.

126. Tronche, F., et al., Genetic dissection of glucocorticoid receptor function in mice. Curr Opin Genet Dev, 1998. 8(5): p. 532-8.

127. Kellendonk, C., et al., Mutagenesis of the glucocorticoid receptor in mice. $\mathrm{J}$ Steroid Biochem Mol Biol, 1999. 69(1-6): p. 253-9.

128. Bauer, A., et al., The glucocorticoid receptor is required for stress erythropoiesis. Genes Dev, 1999. 13(22): p. 2996-3002.

129. Reichardt, H.M., et al., DNA binding of the glucocorticoid receptor is not essential for survival. Cell, 1998. 93(4): p. 531-41.

130. Bayo, P., et al., Glucocorticoid receptor is required for skin barrier competence. Endocrinology, 2008. 149(3): p. 1377-88.

131. Donet, E., et al., Transrepression function of the glucocorticoid receptor regulates eyelid development and keratinocyte proliferation but is not sufficient to prevent skin chronic inflammation. Mol Endocrinol, 2008. 22(4): p. 799-812.

132. Gould, E., et al., Adrenal hormones suppress cell division in the adult rat dentate gyrus. J Neurosci, 1992. 12(9): p. 3642-50.

133. Cameron, H.A. and E. Gould, Adult neurogenesis is regulated by adrenal steroids in the dentate gyrus. Neuroscience, 1994. 61(2): p. 203-9.

134. Mirescu, C. and E. Gould, Stress and adult neurogenesis. Hippocampus, 2006. 16(3): p. 233-8. 
135. Meerlo, P., et al., New neurons in the adult brain: the role of sleep and consequences of sleep loss. Sleep Med Rev, 2009. 13(3): p. 187-94.

136. Sloviter, R.S., et al., Selective loss of hippocampal granule cells in the mature rat brain after adrenalectomy. Science, 1989. 243(4890): p. 535-8.

137. Gould, E., C.S. Woolley, and B.S. McEwen, Short-term glucocorticoid manipulations affect neuronal morphology and survival in the adult dentate gyrus. Neuroscience, 1990. 37(2): p. 367-75.

138. Woolley, C.S., et al., Effects of aldosterone or RU28362 treatment on adrenalectomy-induced cell death in the dentate gyrus of the adult rat. Brain Res, 1991. 554(1-2): p. 312-5.

139. Hornsby, C.D., J. Grootendorst, and E.R. de Kloet, Dexamethasone Does Not Prevent Seven-Day ADX-Induced Apoptosis in the Dentate Gyrus of the Rat Hippocampus. Stress, 1996. 1(1): p. 51-64.

140. Sloviter, R.S., A.L. Sollas, and S. Neubort, Hippocampal dentate granule cell degeneration after adrenalectomy in the rat is not reversed by dexamethasone. Brain Res, 1995. 682(1-2): p. 227-30.

141. Almeida, O.F., et al., Subtle shifts in the ratio between pro- and antiapoptotic molecules after activation of corticosteroid receptors decide neuronal fate. FASEB J, 2000. 14(5): p. 779-90.

142. Crochemore, C., et al., Direct targeting of hippocampal neurons for apoptosis by glucocorticoids is reversible by mineralocorticoid receptor activation. Mol Psychiatry, 2005. 10(8): p. 790-8.

143. Tronche, F., et al., Disruption of the glucocorticoid receptor gene in the nervous system results in reduced anxiety. Nat Genet, 1999. 23(1): p. 99-103.

144. Gass, P., et al., Genetic disruption of mineralocorticoid receptor leads to impaired neurogenesis and granule cell degeneration in the hippocampus of adult mice. EMBO Rep, 2000. 1(5): p. 447-51.

145. Berger, S., et al., Loss of the limbic mineralocorticoid receptor impairs behavioral plasticity. Proc Natl Acad Sci U S A, 2006. 103(1): p. 195-200.

146. Huang, G.J. and J. Herbert, Stimulation of neurogenesis in the hippocampus of the adult rat by fluoxetine requires rhythmic change in corticosterone. Biol Psychiatry, 2006. 59(7): p. 619-24.

147. Pinnock, S.B., et al., Interactions between nitric oxide and corticosterone in the regulation of progenitor cell proliferation in the dentate gyrus of the adult rat. Neuropsychopharmacology, 2007. 32(2): p. 493-504.

148. Pinnock, S.B. and J. Herbert, Brain-derived neurotropic factor and neurogenesis in the adult rat dentate gyrus: interactions with corticosterone. Eur J Neurosci, 2008. 27(10): p. 2493-500.

149. Stavreva, D.A., et al., Ultradian hormone stimulation induces glucocorticoid receptor-mediated pulses of gene transcription. Nat Cell Biol, 2009. 11(9): p. 1093-102.

150. Kochman, L.J., et al., Circadian variation in mouse hippocampal cell proliferation. Neurosci Lett, 2006. 406(3): p. 256-9.

151. Ambrogini, P., et al., Persistently high corticosterone levels but not normal circadian fluctuations of the hormone affect cell proliferation in the adult rat dentate gyrus. Neuroendocrinology, 2002. 76(6): p. 366-72.

152. van der Borght, K., et al., Hippocampal cell proliferation across the day: increase by running wheel activity, but no effect of sleep and wakefulness. Behav Brain Res, 2006. 167(1): p. 36-41. 
153. Holmes, M.M., et al., Adult hippocampal neurogenesis and voluntary running activity: circadian and dose-dependent effects. J Neurosci Res, 2004. 76(2): p. 216-22.

154. Borgs, L., et al., Period 2 regulates neural stem/progenitor cell proliferation in the adult hippocampus. BMC Neurosci, 2009. 10: p. 30.

155. Yang, S., et al., The role of mPer 2 clock gene in glucocorticoid and feeding rhythms. Endocrinology, 2009. 150(5): p. 2153-60.

156. Smaaland, R., et al., Rhythms in human bone marrow and blood cells. Chronobiol Int, 2002. 19(1): p. 101-27.

157. Bjarnason, G.A. and R. Jordan, Rhythms in human gastrointestinal mucosa and skin. Chronobiol Int, 2002. 19(1): p. 129-40.

158. Brown, W.R., A review and mathematical analysis of circadian rhythms in cell proliferation in mouse, rat, and human epidermis. J Invest Dermatol, 1991. 97(2): p. 273-80.

159. Cardoso, S.S. and A.L. Ferreira, Effect of adrenalectomy and of dexamethasone upon circadian distribution of mitosis in the cornea of rats. I. Proc Soc Exp Biol Med, 1967. 125(4): p. 1254-9.

160. Barbason, H., et al., Circadian synchronization of liver regeneration in adult rats: the role played by adrenal hormones. Cell Tissue Kinet, 1989. 22(6): p. 451-60.

161. Dickmeis, T., et al., Glucocorticoids play a key role in circadian cell cycle rhythms. PLoS Biol, 2007. 5(4): p. e78.

162. Dekens, M.P., et al., Light regulates the cell cycle in zebrafish. Curr Biol, 2003. 13(23): p. 2051-7.

163. Rojas-Munoz, A., R. Dahm, and C. Nusslein-Volhard, chokh/rx3 specifies the retinal pigment epithelium fate independently of eye morphogenesis. Dev Biol, 2005. 288(2): p. 348-62.

164. Nica, G., et al., Zebrafish pit1 mutants lack three pituitary cell types and develop severe dwarfism. Mol Endocrinol, 2004. 18(5): p. 1196-209.

165. Renner, K., M.J. Ausserlechner, and R. Kofler, A conceptual view on glucocorticoid-lnduced apoptosis, cell cycle arrest and glucocorticoid resistance in lymphoblastic leukemia. Curr Mol Med, 2003. 3(8): p. 707-17.

166. Kofler, R., The molecular basis of glucocorticoid-induced apoptosis of lymphoblastic leukemia cells. Histochem Cell Biol, 2000. 114(1): p. 1-7.

167. Amsterdam, A. and R. Sasson, The anti-inflammatory action of glucocorticoids is mediated by cell type specific regulation of apoptosis. Mol Cell Endocrinol, 2002. 189(1-2): p. 1-9.

168. Rutz, H.P., Effects of corticosteroid use on treatment of solid tumours. Lancet, 2002. 360(9349): p. 1969-70.

169. Herr, I., et al., Regulation of differential pro- and anti-apoptotic signaling by glucocorticoids. Apoptosis, 2007. 12(2): p. 271-91.

170. Buttgereit, F., et al., Efficacy of modified-release versus standard prednisone to reduce duration of morning stiffness of the joints in rheumatoid arthritis (CAPRA-1): a double-blind, randomised controlled trial. Lancet, 2008. 371(9608): p. 205-14.

171. Smolensky, M.H., B. Lemmer, and A.E. Reinberg, Chronobiology and chronotherapy of allergic rhinitis and bronchial asthma. Adv Drug Deliv Rev, 2007. 59(9-10): p. 852-82.

172. Mormont, M.C. and F. Levi, Circadian-system alterations during cancer processes: a review. Int J Cancer, 1997. 70(2): p. 241-7. 
173. Sephton, S.E., et al., Diurnal cortisol rhythm as a predictor of breast cancer survival. J Natl Cancer Inst, 2000. 92(12): p. 994-1000.

174. Loudon, A.S., et al., Ultradian endocrine rhythms are altered by a circadian mutation in the Syrian hamster. Endocrinology, 1994. 135(2): p. 712-8.

\section{Figure legends}

\section{$\underline{\text { Table } 1}$}

Overview of glucocorticoid signalling deficiency effects on various tissue types observed in the studies cited in the text. ADX, adrenalectomy; CRH, corticotropin releasing hormone; CORT, corticosteroids; GR, glucocorticoid receptor; dim/dim, dimerisation mutant; -/-, knock out mutant; $\downarrow$ downregulation; $\uparrow$, upregulation.

\section{$\underline{\text { Table } 2}$}

Overview of the effects of glucocorticoid manipulation on adult hippocampal neurogenesis observed in the studies cited in the text. For details see text. ADX, adrenalectomy; CORT, corticosteroid; CRH, corticotropin releasing hormone; GC, glucocorticoid receptor agonist; GR, glucocorticoid receptor; GR $\operatorname{dim} / \mathrm{dim}$, dimerisation mutant of the GR; MC, mineralocorticoid receptor agonist; MR, mineralocorticoid receptor; -/-, knock out mutant; n.e., not examined; $\downarrow$ downregulation; $\uparrow$, upregulation; $\leftrightarrow$, no change.

\section{$\underline{\text { Fig. } 1}$}

Three dynamic systems interact in glucocorticoid regulated circadian cell proliferation: The circadian clock, the dynamic plasma glucocorticoid levels and the cell cycle. A) Glucocorticoids are released by the adrenal gland in a pulsatile fashion (blue). Superimposed on this rhythm is a circadian rhythm that mainly regulates the 
amplitude of the pulses (red). B) The circadian clock consists of an autoregulatory transcription-translation feedback loop. The clock genes CLOCK (C, blue) and BMAL1 (B, green) activate transcription of the period (per, red) and cryptochrome (cry, orange) genes via E-box enhancer elements (E, white). The PER (P) and CRY (Y) proteins heterodimerise, locate to the nucleus and repress the activity of the CLOCK-BMAL1 heterodimer, thereby downregulating their own expression. Delays in the feedback loop result in oscillating gene expression. C) The cell cycle consists of a dynamic progression of proliferating cells through the gap 1 (G1), DNA synthesis (S), gap 2 (G2) and mitosis (M) phases. Information on the nature of the interfaces between the three systems is currently limited. Some examples are: Interface A-B: Hamsters carrying a mutation which shortens their circadian period also present a reduced ultradian corticosterone pulse frequency [174]. Conversely, steady state transcription levels of the glucocorticoid inducible clock gene perl are different under constant versus pulsatile GC treatments [149]. These examples suggest that, at least in some cases, the circadian clock and the circadian-ultradian GC rhythms may be interdependent. Interface B-C: The circadian clock can directly regulate a number of cell cycle genes [57]. Interface A-C: Depending on the cell type, glucocorticoids can both inhibit and enhance cell proliferation in a variety of systems. They are required for circadian cell cycle progression in zebrafish larvae, thereby connecting all three systems [161]. For details see text.

Fig. 2

Model of the central and peripheral control of glucocorticoid dynamics. A central clock in the SCN drives circadian rhythms of neural activity in projections to various brain targets, including the PVN. A humoral pathway from the SCN to the adrenal 
gland involves release of CRH by neurons of the PVN into the portal system of the pituitary gland (PIT), where CRH stimulates ACTH secretion. Circadian CRH release is controlled mainly via indirect pathways from the SCN. ACTH in turn stimulates glucocorticoid production and release in the adrenal gland. A second, neural pathway connects the SCN with the adrenal gland via the autonomic nervous system. Light input into the adrenal gland is mediated by this pathway, and it may also influence the sensitivity of the gland to ACTH stimulation. A third player in the dynamic regulation of glucocorticoid release is the autonomous circadian clock of the adrenal gland itself, which appears to regulate both the expression of genes of the glucocorticoid synthesis pathway and the sensitivity of the adrenal gland to ACTH. The origin of pulsatile rhythms within this system is less well understood. In peripheral organs (including non-SCN areas of the brain), glucocorticoids bind to glucocorticoid ( $\mathrm{G}$, blue) and mineralocorticoid $(\mathrm{M}$, white) receptors, with each receptor type mediating a different dynamic signalling response. The resulting glucocorticoid signalling activity then interacts with the circadian clock and with cell proliferation. ACTH, adrenocorticotropic hormone; ANS, autonomic nervous system; CRH, Corticotropinreleasing hormone; GC, glucocorticoid; G, glucocorticoid receptor; M, mineralocorticoid receptor; PIT, pituitary; PVN, paraventricular nucleus; SCN, suprachiasmatic nucleus. 
Table 1

\begin{tabular}{|l|l|l|l|}
\hline Type of deficiency & Tissue affected & $\begin{array}{l}\text { Effect of } \\
\text { deficiency on } \\
\text { proliferation }\end{array}$ & References \\
\hline ADX & small intestine & $\downarrow$ & {$[119-121]$} \\
\hline ADX & brain (mainly glia cells) & $\uparrow$ & {$[122,123]$} \\
\hline ADX & $\begin{array}{l}\downarrow \text { hippocampal neurogenesis (granule } \\
\text { cells) }\end{array}$ & $\uparrow$ & $\begin{array}{l}{[132,133] \text { and see }} \\
\text { Table 2 }\end{array}$ \\
\hline CRH -/- (=> CORT $\downarrow$ ) & lung & $\uparrow$ & {$[124,125]$} \\
\hline GR -/-, GR dim/dim & erythrocytes (stress erythropoiesis) & $\downarrow$ & {$[128]$} \\
\hline GR -/- & skin (suprabasal keratinocytes) & $\uparrow$ & {$[130,131]$} \\
\hline
\end{tabular}

Table 2

\begin{tabular}{|l|l|l|l|l|}
\hline $\begin{array}{l}\text { Experimental } \\
\text { manipulation }\end{array}$ & $\begin{array}{l}\text { CORT } \\
\text { levels }\end{array}$ & Proliferation & Apoptosis & References \\
\hline ADX & $\downarrow$ & $\uparrow$ & $\uparrow$ & {$[132,133,136,137]$} \\
\hline+ CORT & $\uparrow$ & $\downarrow$ & n.e. & {$[133]$} \\
\hline+ GC & $\downarrow$ & n.e. & $\uparrow$ & {$[141,142]$} \\
\hline+ MC & n.e. & n.e. & $\begin{array}{l}\text { rescue of GC induced } \\
\text { apoptosis }\end{array}$ & {$[141,142]$} \\
\hline ADX + CORT & $\leftrightarrow \uparrow ?$ & no rescue of ADX effect & rescue of ADX effect & {$[133,137]$} \\
\hline ADX + GC & $\downarrow$ & n.e. & no rescue of ADX effect & {$[139,140]$} \\
\hline ADX + MC & $\downarrow$ & n.e. & rescue of ADX effect & {$[138]$} \\
\hline Brain GR -/- & $\uparrow$ & $\leftrightarrow$ & $\leftrightarrow ?$ & {$[143,144]$} \\
\hline Rescued MR -/- & $\uparrow$ & $\downarrow$ & $\leftrightarrow$ & {$[144]$} \\
\hline Brain MR -/- & $\leftrightarrow$ & $\leftrightarrow ?$ & $\leftrightarrow ?$ & {$[145]$} \\
\hline
\end{tabular}




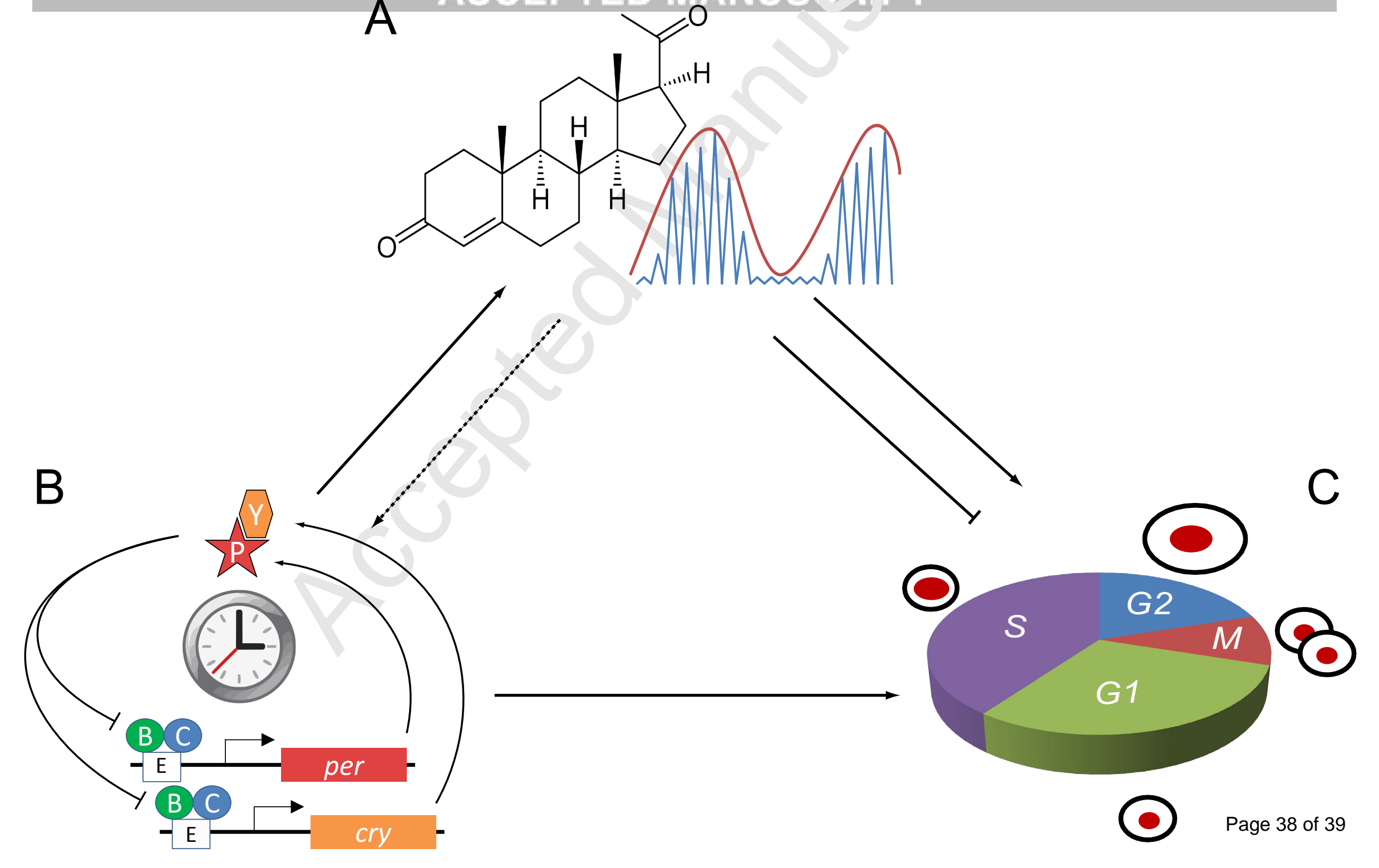


Figure 2

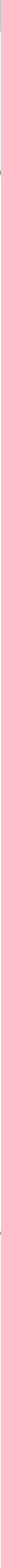

